\title{
The invisible sufferers of the COVID-19 pandemic: Mental health impact and intervention for children and adolescents
}

\author{
Anuja S. Panicker ${ }^{1}$, Chandana Nedungottil ${ }^{2}$ \\ ${ }^{1}$ Professor in Clinical Psychology, Department of Psychiatry, PSG Institute of Medical Sciences and \\ Research, Coimbatore, Tamil Nadu, India.. \\ ${ }^{2}$ Lecturer in Clinical Psychology, Department of Psychiatry, PSG Institute of Medical Sciences and \\ Research, Coimbatore, Tamil Nadu, India.
}

Corresponding author: Chandana Nedungottil

Email - chandanabalakrishnan@gmail.com

\begin{abstract}
Children and adolescents frequently bear the brunt of psychosocial as well as global issues going on in their environment silently. They are particularly vulnerable during public health emergencies like pandemics due to their limited understanding of the event, inadequate coping strategies and inability to communicate their feelings like adults. In the ongoing COVID-19 pandemic, the initial phases of understanding the illness, methods of treatment and disease containment have been formulated and initiated. The next area of priority can focus on the potential short and long-term negative repercussions of such a massive and unpredictable pandemic. This paper focuses in the domains of psychological impact and manifestations in children and adolescents, impact on parents, impact of prolonged school closure and interventions for the same.
\end{abstract}

Keywords: COVID-19, Psychological Impact, Child And Adolescents, Intervention

(Paper received $-28^{\text {th }}$ November 2020, Peer review completed $-5^{\text {th }}$ January 2021)

(Accepted $-8^{\text {th }}$ January 2021)

\section{INTRODUCTION}

Children and adolescents silently bear the brunt of psychosocial as well as global issues going on in their environment. Situations like the ongoing COVID-19 pandemic make them particularly vulnerable due to their limited understanding of the event, inadequate coping strategies, exposure to large amounts of information, high levels of stress and anxiety in adults around them as well as their inability to communicate their feelings like adults. They experience changes in their daily routine and social infrastructure, the same routine which ordinarily foster resilience to challenging events [1]. The rapid rise in the number of infected cases $\&$ deaths, disruption of daily routines, home confinement, fear of infection, social distancing from peers $\&$ friends and lack of access to educational resources can trigger a sense of uncertainty and anxiety among children and adolescents [2]. The response of a child to a crisis situation depends upon multiple factors, such as, the child's prior exposure to emergency situations, physical \& mental health, the socioeconomic circumstances of the family as well as the child's cultural background [2]. In this paper, the short and long-term psychological impact of COVID-19 pandemic in children and adolescents are discussed.

\section{Psychological impact and manifestations}

\section{Young Children}

Young children can perceive environmental changes as well as parental distress. Even children younger than two years can notice the absence of regular caregivers (eg, grandparents) and become unsettled and upset, 
seeking their return [2]. In the context of cognitive development in children, magical thinking influences the thinking patterns in young children within the age of 4-7 years [3], in which children assume that their thoughts, wishes or unrelated actions can cause external events. For example, an illness can be caused by a particular thought or behaviour of the child. This period also overlaps with the development of conscience, that is, a sense of right and wrong, as part of moral development [2]. In the midst of the pandemic, young children tend to form their own hypotheses, as an attempt to comprehend the current situation. Emergence of magical thinking as well as sense of conscience combined with a poor understanding of how the illness is spread, young children can develop a sense of self blame or feeling that illness is a punishment for their previous bad behaviour [4].

The unpredictability children face during the pandemic, both from the external situation as well as familial situations, can be perceived by children as a threat leading to underlying anxiety. In order to avoid triggering further familial insecurities and instabilities, children tend to avoid expressing these conflicting feelings and sharing their own concerns, ultimately leaving children to cope with their feelings on their own [5]. Children screened for behavioural \& emotional distress due to the Covid-19 pandemic have presented with clinginess, distraction, irritability and fear that family members can contract the deadly disease [6]. They may respond to stress in different ways, that is, by becoming clingier and anxious, withdrawn, bedwetting and regressive behaviors [7]. At the same time, children can manifest anxiety as externalizing behaviours, such as acting out or arguing, rather than the more typically assumed tearful, sad, or worried responses [5].

\section{Adolescents}

In the context of psychosocial development, adolescents are also at a crucial stage of development. This transitional period, between 12-19 years of age, of the resolution of ambivalence in role confusion and identity formation [8], paves the way for later self-acceptance and social adjustment in adulthood. This is also an age where adolescent have increased energy levels, curiosity and crave for novelty and exploration. The combination of puberty- related hormonal changes, along with adolescent social dynamics, make them highly attuned to social status, peer group and relationships. From a biological perspective, the areas of the brain like prefrontal cortex which is the seat of insight, judgment and decision making matures to the adult level in adolescence. However, even milder levels of stress during adolescence can impair the cognitive development of the teenager [9].

Adolescents obtain an outlet through participation in social activities, sports and other team activities and interactions with friends and relatives [10]. A lack of outlet for these inner urges due to the current pandemicrelated restrictions in such activities, as well as the impositions of social distancing and home isolation, result in a sense of frustration, which adolescents can present as frequent anger outbursts, nervousness, disconnected, nostalgic and boredom. Also, under uncontrollable stressful conditions they can be susceptible to impaired judgment and impulsive decision making [9].

\section{Children in Quarantine}

Children can be quarantined at home or in local hospitals or collective medical observation centres if the child is infected, suspected of being infected or when caregivers are infected or have died from the disease. Children who are quarantined at home have the advantage that the presence of parents or relatives in a familiar environment could act as buffers and the stress caused by such a sharp change in their environment might be eased to some degree. Children separated from caregivers require special attention as separation from parents or parental loss during childhood has long-term adverse effects on mental health including higher risk of developing mood disorders and psychosis and risk of death by suicide in adulthood [11-12]. Separation from caregivers pushes children into a state of crisis which might increase the risk of psychiatric disorders [13].

Apart from separation from parents, children in quarantine can also be psychologically affected by the negative impact of stigmatization, fear of an unknown disease and social isolation [14]. Children who were isolated or quarantined during pandemic diseases were found to be more likely to develop acute stress disorder, adjustment disorder \&grief and 30\% met clinical criteria for post-traumatic stress disorder [15]. 


\section{Impact on parents}

\section{Parental Stress}

Parental stress has a negative impact on children, as adults' preoccupation with the implications of COVID19 might compromise their ability to sensitively recognize and respond to children's cues or distress [2]. Adults tend to mask their own feelings and focus conversations with the child on the practical aspects of the illness. They also specifically use technical or factual language to try and minimize children's distress [16]. This absence of emotion-focused conversation can induce anxiety and doubts in children regarding the actual emotional state of the adults around them. A study on parents with children less than 12 years of age in the United States has indicated a high level of psychological distress among people who suffered financial losses. Among these parents, 40\% expressed high level of distress secondary to difficulties in dealing with work responsibilities and child care and more than 50\% also admitted that the financial difficulties due to social isolation affected their parenting skills. People financially affected by COVID-19 outbreak are experiencing more psychological distress than others [17].

Parents can also misperceive the stress reactions in children as misbehaviour, oppositional/defiant behaviour, and temper tantrums, resulting in parental self-doubt and sense of inadequacy, difficulty understanding and empathizing, increasing sense of sadness, depression and lack of control, which can in turn trigger parental trauma or stress response [10].

\section{Risk of child abuse and neglect}

Children are also at risk for child abuse and neglect. Previous research in West Africa from previous financial recessions, natural disasters, and outbreaks like the Ebola outbreak from 2014-2016 have revealed increased rates of child abuse [18-19]. Reports of domestic violence to police have tripled during the lockdown since February 2020 in China.10In India, during lockdown over a span of 10 days (March 20-31), from 3.07 lakh calls received by Childline India Foundation (CIF), a free emergency phone service for supporting children, 92000 (30\%) were related to issues related to protection against abuse \& violence against children [20].

Social distancing measures can result in social isolation in an abusive home, in which they are either passive observers of violence or are victims of abuse in the home environment. Witnessing violence in the families and marital discord can have debilitating impact on children. They can be triangulated to the couple subsystem deferring their emotional development and further affecting their mental health [21]. Children witnessing violence between parents can also be a victim of maternal stress, paternal irritability and inconsistent parenting eventually developing externalizing as well as internalizing behaviors [22]. The abuse is also likely to be exacerbated during economic uncertainty \& stress secondary to the ongoing pandemic [23]. Children who are more vulnerable for abuse include those who have a history of previous trauma, physical and or mental health problems, children with parents who are divorced/separated, incarcerated parents or having mental/chronic physical health problems [10]. Children growing up in families from the lower socio-economic strata are particularly vulnerable for abuse and/ or neglect because of possible preexisting psychosocial stressors as well as developmental \& behavioural disorders. Children in unstructured environments with low parental monitoring have increased likelihood for sedentary activities, unintentional injuries as well as engagement in risky health behaviors [24].

\section{Impact of prolonged school closure}

Local and central government bodies and school boards have now started to initiate policies and guidelines for gradual reopening of schools. However, we need to look into the long-term impact of the educational and social isolation that children and adolescents have experienced as they slowly start to emerge from their months of home confinement.

In addition, pandemic-related trauma and economic instability can disproportionately impact children hailing from families of low socio- economic strata of society, particularly those who heavily rely on schoolbased services for nutritional needs such as mid-day meal programs, along with physical and mental health needs [25]. This further exacerbates pre-existing inequalities and widens the learning gap between children from lower-income and higher-income families [26]. 


\section{Inactivity and increased screen time}

When children are out of the school environment (weekends and summer holidays), they tend to be physically less active, have longer screen time, follow irregular sleep patterns and follow less favourable diets, thus making them more prone for weight gain and loss of cardiorespiratory fitness [27]. Irregular sleep patterns and late awakening can be associated with behavioural issues among preschool children [28]. The negative effects on health are likely to be much worse as children are confined to their homes without outdoor activities or interaction same aged friends during the current outbreak [27]. Increased screen time and excessive social media usage can also make children vulnerable to online predators, cyber bullying as well as potentially harmful content [10].

\section{Online learning}

Remote or online learning presents challenge for all families as they require reliable access to technology and a stable learning environment. As parents would also be facing their own pandemic -related stressors (e.g., unemployment, at-risk jobs), they would also lack the time and resources to support remote learning [29]. Children from low-income households live in conditions that make home schooling difficult and are thus at a greater disadvantage.

\section{School closure: Mental health care}

For children with pre-existing mental health difficulties and special needs, school closure can induce a sense of loss of focus in life and [23] possibility of symptom relapse and the lacuna of regular and frequent therapist contact poses as high risk of exacerbations during disasters [30]. Children with Autism express frustration when daily routines are disrupted and are more likely to show problematic behaviors such as irritability, aggression and social withdrawal during such periods $[23,31]$.

\section{Interventions}

Providing information and prioritizing communication with children about COVID-19 is an essential component of any universal, community-led response to the pandemic [2]. Mental Health interventions to previous emergencies and disasters have included widespread psychological first aid focused on psychoeducation about normative reactions and adaptive coping strategies [1].

\section{Parenting style and family bonding}

Appropriate parenting approaches can help to strengthen family bonds as well meet the child's psychological needs [10]. Parents are important role models for healthy behavior in children. Good parenting skills become particularly crucial when children are confined at home [27]. Home confinement secondary to COVID-19 related restrictions can be considered as an opportunity to enhance interaction between parents and children by involving children in family activities and improving their self-sufficiency skills. The family can set a routine for themselves, appropriately dividing and sharing roles and responsibilities. Besides monitoring the child performance and behavior, the child's identity and needs should be respected and encouraged to develop self- discipline skills [32]. Planning multiple activities during the day, including physical activities, can help to reduce screen time. Joint parent-child activities can be planned, whereby set times of the day can be set apart for a few regular activities each day. These can include home tutoring, telephone calls with friends and family, cooking together, family meals, craft activities, etc. Bedtime and mealtime routines can also help children feel safe, organized and secure [27].

\section{Clarity of information and Effective communication}

During stressful times, children require a safe, reassuring and secure relationship with their caregivers, with whom they can openly express their feelings and questions. Sensitive and effective communication about life-threatening illness has been found to have major benefits for children and for the family's long term psychological wellbeing as well [5]. In order to ensure effective communication, it is crucial that the child's developmental stage be taken into consideration so that the family members neither underestimate nor overestimate the child's understanding [32]. The family communication style should focus on normalizing emotional reactions and reassuring children, which would help to contain anxiety [2]. 
Adults require to be open regarding uncertainty and psychological challenges of the pandemic, without overwhelming children with their own fears, offering a coherent explanation for what children are observing, which would in turn grant permission for children to safely talk about own feelings. Direct conversations with children about these issues could alleviate their anxiety and avoid panic. Close and open communication with children can help to identify any physical and psychological issues and for comforting children in prolonged isolation [27-28]. Adults can also refrain from talking about the COVID related situation with other adults or older siblings around them. Currently, children are constantly exposed to epidemic-related news. Children's anxieties can also be aggravated by exposure to media. This can be overcome by avoiding panic provoking news on media, encouraging the positive use of social media - e.g. form support groups, monitoring the screen time and turning off the news channels when young children are around [10].

\section{Specific interventions}

Young children: Detailed analysis of behavioural triggers can also help understand the triggers and maintaining factors. Younger children generally prefer closer proximity, more physical touch, hugging and proximity with the parent as compared to older children, which may be restricted due to current pandemic -related restrictions. If the child is more demanding at nap time and/or bedtime, parents can spend more quality time with the child during daytime and 10-15 minutes breaks where parents focus entirely on the child [10].

Adolescents: For adolescents, home bound physical activities can be encouraged and social interactions can be introduced through videoconferencing, family activities, telephone calls at the same time each day can also be introduced. Sleep pattern can be normalized by avoiding frequent day time naps, avoiding bright (especially blue) light like computer screens at night and sticking to a consistent sleep and wake time [10].

Children in quarantine: Children in quarantine can be encouraged to establish a regular activity schedule. If they are separated from parents, the child's communication time with parents can be increased through mobile devices. Alternate caregivers can also be arranged for reassurance and support $[7,33]$. Children's access to disease information can be increased through comic books and videos. Health care professionals can also be oriented to identification of severe distress, worry, anxiety, difficulty sleeping and loss of appetite and encouraged for timely referral to mental health professionals for further intervention.

Children with special needs: Children with special needs have been reported to experience severe negative repercussions secondary to the suspension of therapy sessions and social skills group. This abrupt discontinuity can not only hinder progress in learning essential skills at each developmental stage, but also result in the loss of acquired skills. Physical isolation from peers and support networks can exacerbate underlying behavioral health issues [23]. To compensate, parents can avoid excessive disruptions in daily routines by establishing a daily schedule of activities that can be carried out in the home environment, which can reduce anxiety induced by uncertainty. Parents can also maintain communication with therapists and schools through online speech and social skills training sessions [23]. Group tele therapy sessions can provide emotional support while maintaining physical distance [30]. At the same time, parents also experience a shrink in their usual social support network because of social distancing and/or COVID-19 illness. Mutual aid resource groups, family/ caregiver support groups and respite child care can be encouraged [30].

\section{CONCLUSION}

Awareness needs to be raised among mental health professionals as well as the general public regarding the potential short- and long- term negative mental health impact on children\& adolescents. Interventions can focus on reassurance, structured family environment and effective, open communication. Parental mental health should also be prioritized. Timely action can help lessen the impact improve long-term capacities for mental health. Monitoring of the mental health of children over a period of time can give an understanding of the long-term impact of the pandemic on their well-being, bereavement secondary to loss and death and issues related to parental unemployment or loss of household income, impact of prolonged school closures and strict social distancing measures. Government policies and school boards can incorporate guidelines 
and principles for effective online learning which ensure contents which meet educational requirements, but at the same time without overburdening the students. Schools can also actively promote a health-conscious schedule, good personal hygiene, encourage physical activities, appropriate diet and integrate such health promotion materials into school curriculum.

It is also important to support vulnerable populations in economically unequal societies to prevent further deepening of these inequalities. In this context, communities can also serve as valuable resources where parent -teacher committees can work together for planning for meeting the children's educational requirements as well as support for disadvantaged students.

\section{REFERENCES}

1. Danese A, Smith P, Chitsabesan P, Dubicka B. Child and adolescent mental health amidst emergencies and disasters. Br J Psychiatry 2020;216(3):159-62.

2. Dalton L, Rapa E, Stein A. Protecting the psychological health of children through effective communication about COVID-19. The Lancet Child Adolesc Health 2020;4(5):346-7.

3. Piaget J. Piaget's theory. In Piaget and his school 1976 (pp. 11-23). Springer, Berlin, Heidelberg. 1976.

4. Edwards M, Davis H. The child's experience. In: Counselling children with chronic medical conditions. Leicester, UK: British Psychological Society 1997:28-48.

5. Dalton L, Rapa E, Ziebland S, Rochat T, Kelly B, Hanington L, Bland R, Yousafzai A, Stein A, Betancourt $\mathrm{T}$, Bluebond-Langner M. Communication with children and adolescents about the diagnosis of a lifethreatening condition in their parent. The Lancet 2019;393(10176):1164-76.

6. Jiao WY, Wang LN, Liu J, Fang SF, Jiao FY, Pettoello-Mantovani M, Somekh E. Behavioral and emotional disorders in children during the COVID-19 epidemic. J Pediatrics 2020;221:264.

7. World Health Organization. Helping children cope with stress during the 2019-nCoV outbreak. Online: https://www. who. int/docs/default-source/coronaviruse/helping-children-cope-withstress-print. pdf. 2020.

8. Erikson EH. Identity and the life cycle: Selected papers. International Universities Press. 1959.

9. Arnsten AF, Shansky RM. Adolescence: vulnerable period for stress-induced prefrontal cortical function? Introduction to part IV. Ann NY Acad Sci 2004;1021(1):143-7.

10. Imran N, Zeshan M, Pervaiz Z. Mental health considerations for children \& adolescents in COVID-19 Pandemic. Pak J Med Sci 2020;36:COVID19-S4.

11. Santavirta T, Santavirta N, Betancourt TS, Gilman SE. Long term mental health outcomes of Finnish children evacuated to Swedish families during the second world war and their non-evacuated siblings: cohort study. BMJ 2015;5;350.

12. Abel KM, Heuvelman HP, Jörgensen L, Magnusson C, Wicks S, Susser E, Hallkvist J, Dalman C. Severe bereavement stress during the prenatal and childhood periods and risk of psychosis in later life: population based cohort study. BMJ 2014;1;348.

13. Norredam M, Nellums L, Nielsen RS, Byberg S, Petersen JH. Incidence of psychiatric disorders among accompanied and unaccompanied asylum-seeking children in Denmark: a nation-wide register-based cohort study. Eur Child Adolesc Psychiatry 2018;27(4):439-46.

14. Liu JJ, Bao Y, Huang X, Shi J, Lu L. Mental health considerations for children quarantined because of COVID-19. The Lancet Child Adolesc Health 2020;4(5):347-9.

15. Sprang G, Silman M. Posttraumatic stress disorder in parents and youth after health-related disasters. Disaster Med Pub Health Prep 2013;7(1):105-10.

16. Krauel K, Simon A, Krause-Hebecker N, Czimbalmos A, Bottomley A, Flechtner H. When a parent has cancer: challenges to patients, their families and health providers. Exp Rev Pharmacoecon Outcomes Res 2012;12(6):795-808.

17. Keeter S. People financially affected by COVID-19 outbreak are experiencing more psychological distress than others. Available fromhttps://www.pewresearch.org/fact-tank/2020/03/30/people-financially-affected-bycovid-19-outbreak-are-experiencing-more-psychological-distress-than-others/ [Accessed on 29September, 2020].

18. Brooks-Gunn J, Schneider W, Waldfogel J. The Great Recession and the risk for child maltreatment. Child Abuse Negl 2013;37(10):721-9.

19. Curtis T, Miller BC, Berry EH. Changes in reports and incidence of child abuse following natural disasters. Child Abuse Negl 2000;24(9):1151-62.

20. Press Trust of India. Coronavirus lockdown- Govt. helpline receives 92,000 calls on child abuse and violence in 11 days. Available from: https://www.thehindu.com/news/national/coronavirus-lockdown-govt-helpline- 
receives-92000-calls-on-child-abuse-and-violence-in-11days/article31287468.ece\# [Accessed 29 September 2020].

21. Bell LG, Bell DC, Nakata Y. Triangulation and adolescent development in the US and Japan. Fam Process 2001;40(2):173-86.

22. Holden GW, Ritchie KL. Linking extreme marital discord, child rearing, and child behavior problems: Evidence from battered women. Child Dev 1991;62(2):311-27.

23. Lee J. Mental health effects of school closures during COVID-19. The Lancet Child Adoles Health. 2020;4(6):421.

24. Rajmil L, De Sanmamed MJ, Choonara I, Faresjö T, Hjern A, Kozyrskyj AL, Lucas PJ, Raat H, Séguin L, Spencer N, Taylor-Robinson D. Impact of the 2008 economic and financial crisis on child health: a systematic review. Int J Environ Res Pub Health 2014;11(6):6528-46.

25. Wang G, Zhang J, Lam SP, Li SX, Jiang Y, Sun W, Chan NY, Kong AP, Zhang Y, Li S, Li AM. Ten-year secular trends in sleep/wake patterns in Shanghai and Hong Kong school-aged children: a tale of two cities. J Clin Sleep Med 2019;15(10):1495-502.

26. Yokomaku A, Misao K, Omoto F, Yamagishi R, Tanaka K, Takada K, Kohyama J. A study of the association between sleep habits and problematic behaviors in preschool children. Chronobiol Int 2008;25(4):549-64.

27. Wang G, Zhang Y, Zhao J, Zhang J, Jiang F. Mitigate the effects of home confinement on children during the COVID-19 outbreak. The Lancet 2020;395(10228):945-7.

28. Vilar-Compte M, Pérez V, Teruel G, Alonso A, Pérez-Escamilla R. Costing of actions to safeguard vulnerable Mexican households with young children from the consequences of COVID-19 social distancing measures. Int J Equity Health 2020;19(1):1-3.

29. Masonbrink AR, Hurley E. Advocating for children during the COVID-19 school closures. Pediatrics 2020;146(3).

30. Wong CA, Ming D, Maslow G, Gifford EJ. Mitigating the impacts of the COVID-19 pandemic response on at-risk children. Pediatrics 2020;145(4):e20200973.

31. Bertelli OM, Scuticchio D, Bianco A, Buonaguro FE, Laghi F, Ghelma F, et al. Advices for managing the COVID-19 outbreak and the associated factors of mental distress for people with intellectual disability and autism spectrum disorder with high and very high support needs. Version 1.5. SIDiN (Italian Society for Neurodevelopmental Disorders).

32. Stein A, Dalton L, Rapa E, Bluebond-Langner M, Hanington L, Stein KF, Ziebland S, Rochat T, Harrop E, Kelly B, Bland R. Communication with children and adolescents about the diagnosis of their own lifethreatening condition. The Lancet 2019;393(10176):1150-63.

33. Kumar A, Nayar KR. COVID 19 and its mental health consequences. J Ment Health 2020;4:1-2.

$\star * * * * * * * * * * * * * * * * * * * * * * * * * * * * * * * * * * *$

$$
\begin{gathered}
\text { Acknowledgements - Nil } \\
\text { Conflict of Interest - Nil } \\
\text { Funding - Nil }
\end{gathered}
$$

